\title{
Analisa
}

\section{KULTUR BIROKRASI PATRIMONIALISME DALAM PEMERINTAH PROVINSI DAERAH ISTIMEWA YOGYAKARTA 1}

\author{
Wasisto Raharjo Jati 2 \\ Jurusan Politik dan Pemerintahan, FISIPOL UGM \\ Gedung PAU UGM Lt.3 Sayap Timur, \\ Jl. Teknika Utara, Pogung, Yogyakarta-55281. \\ Telp/ Fax: 0274552212 \\ Email : wasisto.raharjo.jati@mail.ugm.ac.id
}

\begin{abstract}
This study aims to analyze patrimonialism bureaucratic culture in the Provincial Government of Yogyakarta. Analysis of the study was conducted by using patrimonialism bureaucracy theory to analyze characteristics of bureaucracy in Yogyakarta. The result shows that patrimonialism in bureaucracy is built by the recruitment of bureaucrats became "abdi dalem"/(servants in the palace); patrimonialism in bureaucracy also creates hybrid system which consist of modernity and traditional values; king as the governor using the bureaucracy to strengthen the loyalty of the people; patrimonialism establishes mutual relationships where bureaucracy need noble status to enhance their social status in society and sultan needs support from bureaucrats in order to maintain the stability of power: patrimonialism is manifested in the political mobilization of bureaucrats to support sultan become governor in the discussion of the privileges of Yogyakarta.
\end{abstract}

Keywords : patrimonialism bureaucratic, “abdi dalem”, sultanate of Yogyakarta.

\section{Intisari}

Studi ini bertujuan untuk mengkaji kultur birokrasi patrimonialisme yang berada di Pemerintahan Provinsi DIY. Analisa dalam studi ini menggunakan teori birokrasi patrimonialisme dalam menganalisa studi kasus birokrasi di DIY. Hasil studi menunjukkan bahwa patrimonialisme dalam birokrasi dibangun melalui sistem rekrutmen abdi dalem; patrimonialisme dalam birokrasi juga menciptakan sistem birokrasi campuran atau hibrid yang mana terdiri dari nilai modernitas dan tradisional; raja selaku gubernur menggunakan birokrasi untuk memperkuat loyalitas masyarakat; patrimonialisme menciptakan relasi mutualisme raja selaku gubernur menggunakan birokrasi untuk memperkuat loyalitas masyarakat; patrimonialisme menciptakan relasi

${ }^{1}$ Naskah diterima: 5 Juni 2012, revisi pertama: 16 Juli 2012, revisi kedua: 26 Juli 2012, revisi terakhir: 28 Juli 2012 
mutualisme dimana birokrat membutuhkan gelar kerajaan untuk menaikkan status sosial dan Sultan membutuhkan dukungan agar menjaga stabilitas kekuasaan dan Sultan membutuhkan dukungan agar menjaga stabilitas kekuasaan; patrimonialisme dimanifestasikan dalam mobilisasi politis para birokrat untuk mendukung Sultan menjadi gubernur dalam pembahasan RUUK DIY.

Kata kunci: patrimonialisme birokrasi, abdi dalem, kerajaan Yogyakarta

\section{A. PENDAHULUAN}

Sekretaris Provinsi Daerah Istimewa Yogyakarta (DIY), Tri Harjun Ismaji, melalui Surat Edaran (SE) Sekretaris Provinsi Daerah Istimewa Yogyakarta No. 800/3945 tanggal 13 Nopember 2009 perihal Arahan PNS di Lingkungan Pemprov DIY Menjadi Abdi DalemKeraton Yogyakarta, menghimbau agar para birokrat di lingkungan Pemprov DIY menjadi abdi dalemdalam rangka ikut berpartisipasi secara aktif mempertahankan dan melestarikan kebudayaan tradisional Jawa.

Dalam surat tersebut diterangkan pula bahwa semua pimpinan Satuan Kerja Perangkat Daerah (SKPD) diharuskan memberikan suri teladan dengan menjadi abdi dalem Keraton Yogyakarta baik dalam internal birokrasi maupun kepada masyarakat luas dan juga memberikan motivasi atau dorongan kepada PNS di lingkungan SKPD masing-masing untuk menjadi abdi dalem Keraton Yogyakarta. Meskipun surat edaran tersebut sifatnya hanya imbauan dan tidak memaksa bagi birokrat untuk menjadi abdi dalem, namun berbagai kalangan menilai bahwa surat edaran tersebut bermakna politis.2

Hal itu sama saja dengan kian meneguhkan budaya kerajaan dalam sistem birokrasi modern dan akan membuat rancu dalam menilai Sultan sebagai gubernur ataukah raja. Persoalan yang kemudian berkembang ialah nanti munculnya pencampuradukan antara kultur kerajaan dengan birokrasi modern sehingga struktur patrimonialisme kian menancap kuat dalam kinerja para birokrat di lingkungan Pemprov DIY. Dalam hal ini, Surat edaran tersebut merupakan suatu cara bagi pihak kerajaan untuk mengikat bagi birokrat pemerintahan dan juga masyarakat untuk menjadi abdi dalem. Menurut Suwarno (1994), makna abdi dalem dalam era modern sekarang ini memiliki makna penting yakni pihak kerajaan bisa mengukur tingkat loyalitas maupun penerimaan masyarakat Yogyakarta terhadap

${ }^{2}$ Prof. Dr. Warsito Utomo, salah seorang pengajar di MAP (Magister Administrasi Publik) UGM dalam acara diskusi panel MAP (5/1/10) menilai bahwa surat edaran itu bernuansa politik karena surat itu muncul bersamaan dengan polemik Keistimewaan DIY. Warsito Utomo menilai surat itu merupakan upaya konsolidasi politik Sultan dalam meraih dukungan masyarakat Yogyakarta melalui abdidalemisasi birokrat untuk mendukung penetapan Sultan menjadi gubernur dimana seharusnya birokrat merupakan entitas netral yang terbebas dari kepentingan politik penguasa. Selain itu, kritikan juga hadir dari Tri Ratnawati, peneliti politik di P2P LIPI, yang menilai kebijakan abdidalemisasi PNS tersebut merupakan langkah yang diperlihatkan Sultan sehubungan dengan berlarutnya RUUK DIY. Upaya abdidalemisasi ini menimbulkan dilema loyalitas PNS antara kepada Sultan atau kepada pusat (Ratnawati, $2011: 56$ ). 
kekuasaan kasultanan maupun kadipaten dalam menjalankan fungsi administrasi pemerintahan provinsi dan fungsi pelestrasi khazanah budaya Jawa. Sehingga pegawai provinsi yang menjalankan fungsi abdi dalem di kerajaan merupakan simbolisasi loyalitas dari kalangan birokrat. Abdi dalem merupakan bagian dari kesatuan bulat dari Nagari Ngayogyakarta Hadiningrat (nama resmi Kasultanan Yogyakarta) dan juga menjadi pengawal budaya Jawa yang diwajibkan memiliki pengamalan nilainilai berikut yakni (pengangen-angen ingkang luhur), komitmen terhadap kesanggupan atau tugas(tumindak sarta setia (tuhu) dhumateng kesagahan), memiliki integritas moral (ngutamakaken tumindak ingkang sae sarta prayogi) dan memiliki nurani yang bersih (wening lan jujur manahipun). Besarnya peran dualisme antara menjadi birokrat dan abdi dalem inilah yang kemudian mendapatkan status sosial yang bergengsi dalam kehidupan masyarakat. Masyarakat Yogyakarta menilai menjadi birokrat dapat menaikkan citra dan pamor di lingkungan tempat tinggalnya. Hal tersebut tidak telepas dari karakter orang Jawa yang cenderung mengejar status sosial, status kebangsawanan, maupun status terpelajar untuk mendapat pengakuan dari sekitarnya. Radjiman (2002) menilai abdi dalem juga disebut kelompok birokrasi yang birokratik. Kelompok ini sangat banyak jumlah dan jenisnya. Kekuatan dan kewibawaan birokrasi raja di bidang penguasaan dan penyelenggaraan pemerintahan kerajaan terletak pada kekuatan dan kemantapan birokrasi ini.

Dalam relasi birokrat dengan warga masyarakat lainnya, para birokrat memperlihatkan simbolisasi tradisional untuk memperkuat legitimasinya di mata masyarakat dengan lambang Kasultanan Yog y a k a r a, g a mbar S u l t a n Hamengkubuwono X dan Paku Alam IX, serta lukisan wayang yang "diwajibkan" ada dipasang baik di alat transportasi maupun lingkungan instansi kerja untuk menimbulkan kesan keningratan dan kebangsawanan. Apalagi dikaitkan dengan isu RUU Keistimewaan DIY yang hingga kini belum selesai dibahas, adanya birokrasi menjadi abdi dalem menjadikan birokrasi tidak netral karena adanya mobilisasi birokrat untuk kian menjunjung kekuasaan kerajaan di atas masyarakat.

Maka pertanyaan penelitian yang ingin dijawab dalam studi ini adalah bagaimana bentuk birokrasi patrimonialisme yang berkembang di Pemprov DIY?

\section{B. T E O R I BIROKRASI PATRIMONIALISME}

Te or is a s m e n g e n a i patrimonialisme dalam birokrasi dalam kajian ilmu politik di Indonesia dilakukan oleh berbagai Indonesianis seperti halnya Donald K. Emmerson (1983). Adapun lokus mengenai studi patrimonialisme yang dilakukan oleh Emmerson adalah dengan meneliti struktur birokrasi yang terdapat di pemerintahan Orde Baru. Dalam menjelaskan kasus patrimonalisme birokrasi di Indonesia, para Indonesianis ini mencoba mengkomparasikan kasus serupa yang terjadi dalam masa feodalisme Eropa pada abad 13-15. Patrimonalisme sendiri merujuk pada sentralisasi 
kekuasaan yang berpusat pada penguasa perseorangan tertentu (kingship rulerships) yang mengakumulasikan kekuasaan, sedangkan yang lain mengidentifikasikan kepentingannya. Penguasa membagikan sumber daya kekuasaannya kepada pihak yang dapat dipercaya dan memiliki pengaruh besar di masyarakat untuk menjaga keberlangsungan dan stabilitas kekuasaannya. Sementara, bagi pihak yang berkepentingan tersebut memiliki aksesibilitas dalam mencari perlindungan politis maupun ekonomi dalam struktur kekuasaan tersebut. Hubungan tersebut berlangsung dalam pertukaran keuntungan (advantage exchange) yang dijaga dengan rapi oleh kedua belah pihak. Santoso (1997) menilai semasa Orde Baru berkuasa dikenal istilah "ABG" yakni akronim untuk menyebutkan ABRI-BirokratGolkar sebagai tiga serangkai saluran patrimonialisme kekuasaan Presiden Soeharto dalam menjaga stabilitas dan soliditas pemerintahannya. ABRI digunakan untuk mendisiplinkan dan mengatur masyarakat, Birokrat digunakan untuk mengendalikan administrasi pemerintahan, dan Golkar untuk menyeragamkan pilihan politis masyarakat untuk mendukung Presiden Soeharto. Dibandingkan dengan ABRI, relasi Golkar dan Birokat memang sangatlah kuat untuk menunjukkan patrimoni kekuasaan tersebut karena sinergi keduanya memiliki pengaruh kuat dan signifikan hingga pelosok masyarakat. James C. Scott (1993) menilai kekuasaan patrimonial yang berlangsung di Indonesia memiliki akar antropologis kuat yang diwujudkan dalam 'patron-client' atau 'solidaritas vertikal' dapat dilihat dari beberapa hal, diantaranya adalah adanya hubungan antara client-hamba dengan patron-tuan yang diibaratkan sebagai suatu hubungan pertukaran yang vertikal, dimana perubahanperubahan selalu berada di bawah legitimasi kaum elit. Terbentuknya relasi tersebut lebih didasarkan pada ketidaksamaan' dan 'fleksibilitas yang tersebar' sebagai sebuah sistem pertukaran pribadi. Oleh karena itulah, pola internalisasi nilai dan norma penguasa diterima meluas sehingga timbullah kekuasaan yang hegemonik. Adapun kerangka kekuasaan yang hegemonik tersebut dapat diwujudkan dalam model masyarakat prismatik. Fred Riggs (1964) dalam karyanya Administration in Developing Countries: The Theory of Prismatic Society mendefinisikan masyarakat primastik sebagai bentuk transisi masyarakat dari era tradisional menuju modern yang belum selesai dikarenakan adanya benturan nilai modern dan tradisional tersebut. Benturan budaya tersebut dikarenakan masih kuatnya nilai tradisional-kultural di saat nilai modernitas mulai menyebar dalam karakter sosiologis masyarakat. Contohnya dapat kita lihat adanya monopoli kekuasaan yang dimiliki kelompok masyarakat tertentu dengan mengandalkan adanya sumber kuasa tradisional-kharismatik meskipun pada saat yang sama demokrasi telah menyebar dan mempersilakan semua orang untuk terlibat dalam suksesi pemerintahan. Pola masyarakat prismatik inilah yang menjadi karakter birokrat di Provinsi Daerah Istimewa Yogyakarta (DIY) dimana secara struktural, birokrasi menampakkan ciri-ciri sebagaimana layaknya birokrasi 
modern; namun secara kultural, birokrasi masih membawa semangat kuasa kerajaan dalam setiap aspek roda pemerintahannya. Oleh karena itulah kultur birokrasi di Yogyakarta sering kali disebut sebagai "Birokrasi Mataraman". Pendapat itu dikemukakan dengan maksud untuk menggambarkan kuatnya pengaruh budaya kerajaan yang begitu kental terhadap sistem birokrasi di Yogyakarta. Menurut Raharjo (1998), birokrasi mataraman dapat didefinisikan sebagai birokrasi yang hidup dan bekerja pada Kerajaan Mataram. Namun demikian, pengertian birokrasi mataraman sendiri memiliki makna yang meluas terutama dalam pengaturan norma, nilai, maupun prinsipal masyarakat yang dilakukan oleh pihak kerajaan melalui birokrasi. Adapun corak birokrasi mataraman ini berkembang pesat terutama pada daerah berstatus vorstenlanden selama era kolonialisme Belanda yang memiliki sistem kewenangan mengatur rumah tangga pemerintahannya tersendiri yang diakui oleh pihak pemerintah kolonial.з Hal itulah yang kemudian memungkinkan bagi Kasultanan Yogyakarta maupun Kadipaten Pakualaman memelihara kultur birokrasi mataraman tersebut yang berbeda dengan administrasi birokrasi kolonial.

Adapun sistem kekuasaan patrimonialisme yang berada di Kerajaan Mataram sendiri dibangun atas prinsip priyayi-kawula. Priyayi sendiri merupakan kelas bangsawan yang dipekerjakan sebagai pegawai administrasi kerajaan di berbagai instansi (tepas) kerajaan dan kawula merupakan rakyat biasa. Menurut Kartodirdjo (1987) priyayi merupakan kelas terhormat bagi kawula karena status dan materi yang dimilikinya sehingga memiliki kekuasaan terhadap kawula. Kekuasaan tersebut tercermin dari pengusahaan tanah-tanah kerajaan yang dikelola priyayi kepada kawula yang amat tergantung dari tanah tersebut untuk digarap menjadi lahan pertanian maupun permukiman.

Dalam hal ini birokrasi priyayi tersebut dikembangkanlah model kepegawaian sipil kerajaan yang dinamakan 'praja' Sistem praja sebagai bentuk birokrasi Jawa ini kemudian mengalami percabangan menjadi dua bagian penting yakni pamong praja dan pangreh praja. istilah Pamong paling tidak menekankan pada seorang pelayan publik agar mampu mengemong (melayani), ngomong (berkomunikasi) dan siap di-omong (dinilai). Maka, pamong praja diartikan sebagai birokrasi yang mengurus pemerintahan negara. Maknanya, birokrasi Jawa dibentuk untuk melayani rakyat sebagaimana mengasuh anak, penuh perlindungan dan kasih sayang selama kapanpun. Jika pamong praja ini dibentuk untuk melayani kepentingan publik, maka pangreh praja ini dikhususkan untuk

\footnotetext{
${ }^{3}$ Vorstenlanden merupakan daerah otonomi kerajaan yang merdeka dan diakui eksistensi pemerintahannya oleh Belanda yang diatur dalam Desentralische Wet 1930. Dalam hal ini, daerah yang berstatus vorstenlanden adalah Yogyakarta dan Surakarta yang memiliki wilayah tersendiri. Dalam perkembangannya daerah vorstenlanden sendiri kemudian dikukuhkan dalam status Daerah Istimewa pada masa Republik Indonesia dimana Yogyakarta dan Surakarta berubah menjadi provinsi dengan label DIY dan DIS. Namun demikian, DIS kemudian ditiadakan dan diintegrasikan ke Provinsi Jawa Tengah karena adanya huru-hara revolusi kemerdekaan di Surakarta pada tahun 1947 sehingga mengakibatkan instabilitas pemerintahan DIS. Oleh karena itulah, DIY yang hingga kini masih mempertahankan corak khasnya sebagai daerah kerajaan berikut cara pengaturan birokrasinya.
} 
melayani raja. Istilah pangreh praja sendiri merujuk pengertian kekuasaan penguasa / raja sehingga birokrasi ini dibentuk untuk mempertahankan stabilitas kekuasaan politis raja. Dalam perkembangannya kemudian, pamong kemudian dilebur ke dalam pangreh untuk memperkuat sistem administrasi kerajaan. Meleburnya sistem pamong yang populis menjadi pangreh yang elitis inilah yang kemudian turut berpengaruh pada karakteristik birokrasi yang mengedepankan pendekatan tradisional terlebih dahulu baru kemudian pendekatan rasional. Pola kekuasaan patrimonial yang dilakukan pangreh praja sebagai bentuk nyata corak birokrasi mataraman tersebut memanfaatkan politisasi kultur Jawa yang memiliki karakter statis dan homogen yang lebih mengedepankan adanya harmonisasi dan perdamaian dalam kehidupan. Namun demikian, bentuk "patrimonial" telah dikaitkan pada kegigihan perspektif budaya jawa tradisional akan kekuasaan. Pemegang kekuasaan dan gejala kekuasaan dipandang sebagai sesuatu kesatuan yang nyata. Kegiatan politik dianggap pada si pemegang kekuasaan, dan struktur politik menggantung dalam bentuk jaringan-jaringan vertikal yang saling bersaing untuk memperoleh perlindungan pribadi dari para pemegang kekuasaan.

Maka pengertian priyayi sendiri kemudian berkembang tidak lagi untuk menyebutkan para kerabat kraton dan kaum bangsawan diakui memiliki kedudukan sosial yang tinggi, sehingga seolah terlepas dari atribut pribumi. Makna priyayi kemudian berkembang terutama paska kolonialisme berakhir di Nusantara dan
Yogyakarta berintegrasi ke dalam wilayah republik dimana orang yang mengenyam pendidikan formal yang kemudian duduk sebagai birokrat di pemerintahan disebut sebagai priyayi modern untuk membedakan dirinya dengan priyayi tradisional yang memiliki darah biru atau paling tidak memiliki kerterkaitan dan kedekatan dengan pihak kerajaan maupun kebangsawanan. Diperkenalkannya sistem birokrasi modern dalam pemerintahan Provinsi DIY sendiri tidak lantas kemudian menghilangkan nuansa kerajaan karena jabatan struktural modern yang diperankannya dalam nuansa kultur tradisional sehingga kultur priyayi kerajaan sebagai birokrat belum bisa direduksi. Meskipun wacana reformasi birokrasi mengamanatkan adanya penghilangan garis hierarki vertikal dalam sistem birokrasi, namun para priyayi modern justru masih ada dengan mempertahankan hubungan vertikal dalam kelembagaan dinas maupun badan provinsi lainnya (Basri, 2010 : 22). Perilaku komando vertikal tersebut mendeskripsikan karakter asli sistem feudal kerajaan. Mereka cenderung menganggap masyarakat/rakyat sebagai golongan yang perlu menghormati kedudukan mereka sebagai birokrat. Mereka mentabukan kritikdan kontrol dari bawahan dikarenakan sistem feodalistik melembagakan hubungan vertikal dan hirarkis (yang tajam) dengan bawahan. Berkembangnya kultur priyayi dalam birokrasi modern sebagian besar terbentuk dari pola pangreh praja yang tampil sebagai kekuatan konservatif yang mempertahankan status quo. Selain karena fungsi pelindung tatatentrem, konservatisme juga 
diperlukan untuk melindungi

kedudukannya sendiri merupakan ciri

khas birokrasi priyayi ini. Dalam aspek

yang lain dimensi mempertahankan

status quo tersebut erat kaitannya

dengan mempertahankan nilai-nilai

kultur tradisional ke dalam sistem

birokrasi modern.4

Adapun ciri lainnya yang tidak kalah menonjol adalah bukan hanya peraturan-peraturan sebagai aspek rasional-legal, akan tetapi yang lebih penting lagi adalah tradisi kharisma, yaitu tradisi kemampuan untuk mengilhami pengikut dengan rasa panutan, rasa permisif kepada atasan, sikap arogan rutin yang dijalankan oleh atasan kepada bawahan, kepatuhan, pengabdian dan semangat kerja. Sikap kharismatik tersebut biasanya didorong oleh adanya tingginya gelar akademik, tingginya tingkat eselon kepangkatan, dan juga kalau bisa ditambah gelar tradisional yang diberikan oleh pihak kerajaan yang dibuktikan dengan surat kekancingan. Meskipun secara makro, pemberian gelar tradisional sendiri kini sudah berpengaruh dalam struktur sosial-kultural sebagian kecil masyarakat seiring dengan modernitas zaman. Namun demikian bagi kalangan birokrat yang mengabdi dan bekerja di jajaran pemerintahan Provinsi Daerah Istimewa Yogyakarta (DIY) dan kalangan mayoritas masyarakat kawula Yog y a k art a, pe mberi a n ge la r tradisional dari pihak kerajaan merupakan bentuk prestise tersendiri bagi masyarakat karena sudah "dianggap" sebagai bagian dari pihak kerajaan sehingga mendapatkan penghormatan dari masyarakat. Dalam menjalani profesi sebagai birokrat adanya gelar tradisional kerajaan yang tersemat di nama pegawai tersebut maka akan disegani oleh pihak lain sesama birokrat, terlebih lagi apabila yang mendapatkan gelar tersebut sudah berpangkat dan memiliki karir eselon yang tinggi dalam sistem struktur birokrasi. Implikasinya berdampak pada munculnya sistem bapakisme dalam birokrat. Bapakisme tersebut bisa terlihat dari etika pergaulan antar sesama birokrat yang terdapat di lingkungan kantor pemerintahan Provinsi DIY dimana panggilan "rama" dari birokrat junior kepada seniornya yang mempunyai tingkat eselon tinggi. Kata "rama" merupakan Bahasa Jawa krama halus untuk menyebut bapak / ayah, "rama" sendiri biasanya diucapkan anak kepada bapaknya sebagai bentuk penghormatan maupun tanda bakti karena ayah telah membesarkan dan merawat si anak yang umunya etika tersebut dalam lingkungan keluarga kerajaan.s Dalam konteks birokrasi, "rama" sendiri dipahami sebagai bentuk penghormatan bagi birokrat junior atas perlindungan maupun bimbingan senior kepada juniornya karena telah diberi tunjangan gaji dan kenaikan pangkat yang lumayan atas kesetiannya kepada atasan seniornya.

\footnotetext{
${ }^{4}$ Status quo juga bisa dimaknai tetap mempertahankan Sultan sebagai gubernur sebagaimana yang sudah berjalan selama ini sehingga birokrat tetap nyaman dengan kondisi seperti ini dan tidak menginginkan perubahan secara mendasar utamanya dalam kepemimpinan gubernuran.

${ }^{5}$ krama halus merupakan bagian dari stratifikasi dalam Bahasa Jawa yang terdiri dari empat tingkatan yakni krama inggil, krama halus, ngoko halus, ngoko. Adanya tingkatan dalam bahasa tersebut adalah untuk mempertahankan kastanisasi dalam masyarakat. Penggunaan bahasa krama sendiri digunakan oleh lingkungan kerajaan atau digunakan dalam etika pergaulan antara yang muda kepada yang tua, sementara bahasa ngoko digunakan untuk bahasa sehari-hari rakyat jelata.
} 
Kata "rama" sendiri merupakan bentuk neo-feodalisme dalam birokrasi modern dimana hubungan antara senior dan junior itu tak lebih sebagai suatu pertukaran antara loyalitas/ pengabdian dan jabatan. Apabila tak loyal dan mengabdi secara maksimal pada senior, seorang birokrat junior tidak akan mendapatkan jabatan. Adanya politisasi jabatan antara birokrat senior dan birokrat junior dikarenakan posisi jabatan dianggap sebagai sumber penghasilan material. Semakin tinggi jabatan, maka semakin tinggi pula pendapatan yang diperoleh. Asumsinya ialah bahwa di dalam jabatan itu melekat wewenang besar untuk memperluas kesempatan memperoleh penghasilan.

\section{B I R O K R A T I S A S I A B D I DALEM}

Dalam era demokrasi sekarang ini, abdi dalem masih menjadi cara bagi pihak Kasultanan dan Kadipaten untuk mengikat masyarakat biasa maupun birokrat pemerintahan untuk menjadi bagian integral dari sistem pemerintahan kerajaan sehingga kerajaan bisa mempertahankan struktur hierarkis kekuasaan dengan masyarakat Yogyakarta. Pengertian abdi dalem dalam hal ini bukanlah secara harfiah dimaksudkan sebagai pembantu Sultan, melainkan abdi dalem ini dimaknai sebagai agen simbolisasi budaya dan kekuasaan tradisional Kasultanan dan Kadipaten.

Baik Kasultanan maupun Kadipaten perlu untuk memikirkan strategi untuk mempertahankan eksistensi kekuasaan tradisional sekaligus menjaga hubungan patrimonialnya dengan masyarakat setelah kekuasaan politiknya diserahkan kepada negara. Maka dalam kapasitasnya sebagai daerah istimewa, kerajaan yang juga provinsi ini membentuk sistem birokrasi modern dengan tetap mempertahankan tradisi. Adanya ikatan modernitas dan tradisionalitas dalam sistem birokrasi, menjadikan pemerintahan di Provinsi DIY berbeda dengan daerah lainnya. Maka tidaklah mengherankan, apabila Kasultanan Yogyakarta dan Kadipaten Pakualaman tetap eksis dalam era republik saat ini berkat sistem birokrasi hibrid tersebut dimana birokrasi menjalankan fungsi tradisional yang dikhususkan menjaga hubungan kekuasaan patrimoni dengan masyarakat selain halnya birokrasi tetap memegang nilai birokrasi modern dalam menjalankan roda pemerintahan provinsi.

Adapun dua cara mengikat antara lain, abdi dalem punokawan dan abdi dalem keprajan. Abdi dalem punokawan adalah kesempatan yang diberikan oleh pihak kerajaan Yogyakarta bagi masyarakat luas untuk menjadi abdi dalem. Abdi dalem punokawan atau lebih mudah dipahami sebagai birokrat tradisional yang mengurusi berbagai upacara adat maupun fungsi sosio-kultural dan mengurusi berbagai protokoler internal kerajaan. Layaknya jenjang birokrasi modern, abdi dalem merupakan seoang pegawai yang memiliki tugas pokok dan gaji sesuai dengan pangkat dan kedudukan eselon dan juga memili uang pensiunan disesuaikan loyalitasnya kepada kerajaan dengan menerima uang sebesar 3000 rupiah per bulan beserta tanah kedudukan. Jenjang pangkatnya dari posisi terendah hingga tertinggi meliputi magang, jajar, bekel enom, bekel 
sepuh, lurah enom, lurahsepuh, penewu, wedono, riyo bupati anom, bupati anom, bupati kliwon, bupati nayoko, dan Kanjeng Pangeran Haryo $(\mathrm{KPH})$. Kenaikan pangkat juga mengikuti procedural dalam birokrasi modern yakni empat tahun sekali yang dibuktikan dengan diselenggarakannnya wisuda oleh pihak kerajaan dengan mempertimbangkan kesetiannya menjalankan tugas kerajaan yang terindikasi dari menjalankan tugas di kraton selama satu hingga tiga kali seminggu dengan durasi kerja selam tiga jam yakni dari 09.00 hingga 12.00 maupun mengikuti acara-acara resmi kerajaan yakni sowan bekti, acara ngabekten, grebegan, jamasan pasak, mios dan kudurgongso. Perlu diketahui bahwa, menjadi abdi dalem punokawan sendiri merupakan bentuk panggilan pengabdian kepada kerajaan dan tidak mengejar materi ekonomi selama menjalankan tugas, Memang gaji seorang abdi dalem punokawan dilihat secara numerik tidaklah cukup memeuhi kebutuhan hidup sehari-hari karena gaji dati kerajaan berkisar antara 500 rupiah hingga 3000 rupiah perbulan, Namun demikian, para abdi dalem punokawan justru bisa hidup berkecukupan dengan melakukan sambilan pekerjaan lainnya baik itu bertani, berdagang, maupun berladang. Dalam kultur masyarakat Yogyakarta, menjadi abdi dalem punokawan sendiri merupakan berkah, karena dekat dengan Sultan maka rezeki pun mengalir lancar. Hal tersebut tidak bisa dipungkiri, karena Sultan memiliki aset-aset ekonomi yang banyak untuk diberikan kepada abdi dalem-nya atas balas jasa loyalitasnya. Maka bisa dibilang, relasi antara abdi dalem punokawan dengan Sultan merupakan relasi patrimonialistik yang terbangun dari aspek kultural sebagai Raja dan ekonomi sebagai Tuan Tanah terbesar di Yogyakarta.

Di samping abdi dalem keprajan sebagai birokrasi yang bekerja di pemerintahan provinsi sekaligus menjalankan tugas formalitasnya di kerajaan yakni mengikuti acara resmi maupun upacara adat lainnya. Abdi dalem ini tidaklah menerima gaji dari kerajaan dan birokrat yang menjadi abdi dalem keprajan ini disesuaikan dengan yang dimiliki dalam jenjang kepangkatan Pegawai Negeri Sipil yang dijadikan pijakan untuk memberi pangkat dalam sistem kerajaan yang dilakukan setiap empat tahun sekali dengan menimbang sikap dan perilakunya kepada kerajaan dan pemerintahan. Sultan Hamengkubuwono X selaku raja dan gubernur menilai keberadaan birokrat yang menjadi abdi dalem keprajan sangatlah vital keberadaannya yakni sebagai kekuatan politis administratif dan juga kekuatan sosial kultural. Politis-administratif sendiri dimaknai mobilisasi kekuatan birokrat dalam upaya perjuangan politis menjaga keistimewaan DIY dan sosio-kultural sendiri dimaknai sebagai agen penjaga kebudayaan tradisional kerajaan. Abdi dalem keprajan juga merupakan simbol feodalisme kerajaan terbalut dalam sistem birokrasi modern dimana kata keprajan sendiri konotasinya cenderung mengarah pada pemerintahan kerajaan. Maka dibandingkan dengan abdi dalem punokawan sebagai birokrasi tradisional yang hanya mengurusi urusan kultural dan domestik kerajaan. Abdi dalem keprajan dalam wujud 
birokrasi modern bisa dibilang memegang peran ganda yakni sebagai kekuatan teknokratik-administratif sekaligus juga kekuatan patrimonialisme kerajaan yang sesungguhnya. Oleh karena itulah, $a b d i$ dalem keprajan ini tidaklah netral secara politik dan cenderung memihak Sultan Hamengkubuwono X sebagai gubernur sekaligus pula sebagai seorang Raja. Maka sebagai abdi dalem keprajan, selain menduduki jabatan birokrasi modern juga memiliki jabatan di kerajaan. Selain halnya unsur sipil, abdi dalem keprajan juga berasal dari kalangan militer dan para-militer seperti TNI dan Kepolisian untuk memberi legitimasi kekuasaan kerajaan juga berada di unsur non sipil. Berukut ini perbandingan jenjang kepangkatan abdi dalem baik yang datang dari punokawan (unsur masyarakat) dan keprajan (unsur birokat dan militer).

Tabel 1. Jenjang KepangkatanAbdi Dalem Keprajan (Birokrat) dan Abdi Dalem Punokawan (Masyarakat).

\begin{tabular}{|c|c|c|c|c|c|c|}
\hline \multicolumn{2}{|c|}{ Urutan } & \multirow{2}{*}{ Pangkat } & \multicolumn{2}{|c|}{ Pegawai Negeri Sipil } & \multirow{2}{*}{ Kepolisian } & \multirow{2}{*}{ TNI AD } \\
\hline Punokawan & Keprajan & & Pangkat & Gol. & & \\
\hline 1 & 1 & $\mathrm{KPH}$ & & & Jenderal & Jenderal \\
\hline 2 & 2 & Bupati Nayoko & Pembina Utama & IV e & Kom.Jend & Let.Jend \\
\hline 3 & 3 & Bupati Kliwon & Pem.Ut. Mdy & IV d & Ir. Jend & May.Jend \\
\hline 4 & 4 & Bupati Sepuh & Pem.Ut. Muda & IV c & Brig.Jend & Brig.Jend \\
\hline \multirow[t]{2}{*}{5} & \multirow[t]{2}{*}{5} & \multirow[t]{2}{*}{$\begin{array}{l}\text { Bupati } \\
\text { Anom }\end{array}$} & Pembina I & IV b & $\begin{array}{l}\text { Kombes/ } \\
\text { AKBP }\end{array}$ & $\begin{array}{l}\text { Kolonel / } \\
\text { Let.Kol }\end{array}$ \\
\hline & & & Pembina & IV a & $\begin{array}{l}\text { Komisaris } \\
\text { Polisi }\end{array}$ & $\begin{array}{l}\text { Mayor } \\
\text { Kolonel }\end{array}$ \\
\hline- & 6 & $\begin{array}{l}\text { Riyo } \\
\text { Bupati Anom }\end{array}$ & $\begin{array}{l}\text { Penata I } \\
\text { Penata }\end{array}$ & $\begin{array}{l}\text { III d } \\
\text { III c }\end{array}$ & $\begin{array}{l}\text { AKP } \\
\text { Ip-tu } \\
\text { Ip-da }\end{array}$ & $\begin{array}{l}\text { Kapten } \\
\text { Let-tu } \\
\text { Let-da }\end{array}$ \\
\hline 7 & 7 & Wedono & $\begin{array}{l}\text { Penata Muda I } \\
\text { Penata Muda }\end{array}$ & $\begin{array}{l}\text { III b } \\
\text { III a }\end{array}$ & $\begin{array}{l}\text { A.Ip-tu } \\
\text { A.Ip-da }\end{array}$ & $\begin{array}{l}\text { Pbt. Lettu } \\
\text { Pbt. } \\
\text { Letda }\end{array}$ \\
\hline 8 & 8 & Penewu & $\begin{array}{l}\text { Pengatur I } \\
\text { Pengatur }\end{array}$ & $\begin{array}{l}\text { II d } \\
\text { II c }\end{array}$ & $\begin{array}{l}\text { Brip-ka } \\
\text { Brigpol }\end{array}$ & $\begin{array}{l}\text { Serma } \\
\text { Serda }\end{array}$ \\
\hline 9 & 9 & Lurah & $\begin{array}{l}\text { Peng. Muda I } \\
\text { Peng.Muda }\end{array}$ & $\begin{array}{l}\text { II b } \\
\text { II a }\end{array}$ & $\begin{array}{l}\text { Brip-tu } \\
\text { Brip-da }\end{array}$ & $\begin{array}{l}\text { Ser-tu } \\
\text { Ser-da }\end{array}$ \\
\hline 10 & 10 & Bekel & $\begin{array}{l}\text { Juru I } \\
\text { Juru }\end{array}$ & $\begin{array}{l}\text { Id } \\
\text { Ic }\end{array}$ & $\begin{array}{l}\text { Aj.Brip / } \\
\text { Aj.Briptu } \\
\text { Aj.Bripda }\end{array}$ & $\begin{array}{l}\text { Kopka } \\
\text { Koptu } \\
\text { Kopda }\end{array}$ \\
\hline 11 & 11 & Jajar & $\begin{array}{l}\text { Juru Muda I } \\
\text { Juru }\end{array}$ & $\begin{array}{l}\mathrm{Ib} \\
\mathrm{Ia}\end{array}$ & $\begin{array}{l}\text { Bharaka } \\
\text { Bharatu } \\
\text { Bharada }\end{array}$ & $\begin{array}{l}\text { Praka } \\
\text { Pratu } \\
\text { Prada }\end{array}$ \\
\hline
\end{tabular}

Sumber : Sudaryanto (2008)

Maka, jikalau seorang birokrat yang bekerja di pemerintahan provinsi DIY sendiri golongan III A maupun III B maka akan diberikan pangkat oleh kerajaan sebagai wedono, golongan IV A dan IV B akan diberikan pangkat sebagai bupati anom reh keprajan.
Terkhusus untuk pangkat bupati anom sendiri, pada umumnya pihak kerajaan memberikan pangkat pada birokrat yang memiliki jenjang kepangkatan selevel kepala kantor wilayah, kepala dinas, maupun kepala sub dinas yang membawahi berbagai unit teknis 
maupun fungsional tertentu. Hal itulah yang dialami Kepala Kantor Wilayah Kementerian Agama Prov. DIY, Drs. H. Afandi M.Pd.I yang kemudian diberi kalungguhan sebagai abdi dalem Bupati Anom reh Keprajan Kasultanan Ngayogyakarta Hadiningrat (Majalah Bakti, 2010). Pangkat yang diberikan oleh pihak kerajaan tersebut merupakan bentuk pengakuan dari kerajaan atas kinerjanya selama duduk menjadi birokrat. Namun demikian, di balik pengakuan tersebut tersimpan makna politis kerajaan ingin mengikat berbagai birokrasi level menengah untuk menjadi bagian dari kerajaan. Perkembangannya bisa dilihat dari tabel berikut.

Tabel 2. Jumlah Birokrat yang menjadi Abdi Dalem

\begin{tabular}{c|c}
\hline Tahun & Birokrat Menjadi Abdi Dalem \\
2007 & 72 birokrat \\
2008 & 84 birokrat \\
2009 & 77 birokrat \\
2010 & 156 biroktat \\
2011 & 118 birokrat \\
\hline
\end{tabular}

Sumber : diolah dari berbagai data

Makna politis lainnya seputar abdi dalem keprajan dalam unsur birokrat bisa tersimak pula dari jabatan KPH (Kangjeng Pangeran Haryo) atau KRT (Kangjeng Raden Tumenggung) yang umumnya diberikan kepada bupati dan walikota di Provinsi DIY atau siapa saja yang memegang jabatan birokrat karir tinggi. Hal ini bisa nampak pemberian pangkat tersebut kepada Herry Zudianto, selaku Walikota Yogyakarta periode 20072011 yang mendapat gelar dan pangkat KRT Wasesadipraja, Bupati Sleman, Sri Purnomo mendapat gelar Kanjeng Mas Tumenggung Purnamapradipta, dan Bupati Bantul Sri Surya Widati bergelar Nyai KRT Suryawati.

Gunanya pemberian gelar dan pangkat kepada bupati dan walikota tersebut adalah untuk memperkuat konsolidasi dan memperkuat pengaruh kekuasaan kerajaan di berbagai wilayahnya masing-masing. Pemberian gelar dan pangkat kepada para bupati dan walikota di DIY sendiri merupakan bentuk tradisi bupati pamong praja sebagai warisan dari era birokrasi mataraman lama. Adapun para bupati dan walikota yang tergabung dalam bupati pamong praja sendiri tidak memiliki otonomi melainkan hanya wilayah administratif saja. Artinya pihak kerajaan yang memiliki kekuasaan atas berbagai wilayah tersebut. Oleh karena itulah, meskipun penerapan otonomi daerah di seluruh Indonesia dipusatkan pada kota dan kabupaten. Namun dalam konteks Yogyakarta, pelaksanaan otonomi daerah secara politis dan kultural tetap dipegang Sultan Hamengkubuwono X dan Adipati Paku Alam sebagai kepala daerah provinsi sekaligus penguasa lokal Yogyakarta. Maka para birokrasi level atas sendiri dalam menentukan kebijakan domestik senantiasa meminta pertimbangan kepada pemerintahan provinsi untuk mendapatkan persetujuan. 
Abdi dalem keprajan sendiri juga memperoleh gelar nama profesi bagi yang memiliki ikatan darah dengan kerajaan yang biasanya datang dari keturunan pejabat kerajaan terdahulu yang membawahi berbagai unit tertentu. Maka selain memiliki pangkat kraton, birokrat ini juga memiliki gelar raden atau raden roro yang kemudian ditambahi dengan gelar profesi kerajaan. Adapun macammacam gelar profesi tersebut antara lain :
1) projo : diberikan kepada birokrat teknis di li n g k u n g a n pemerintahan daerah
2) danu : diberikan kepada birokrat yang bekerja mengurusi peternakan
3) karti
: diberikan kepada birokrat yang bekerja di bagian umum
4) tirta
: diberikan kepada birokrat yang bekerja di sektor pengairan
5) dirjo : diberikan kepada birokrat yang bekerja di dinas ekonomi
6) sastro : diberikan kepada birokrat yang bekerja di sektor kepegawaian
7) broto

Daerah (BKD) Provinsi DIY, setelah mendapatkan gelar dan pangkat dari kerajaan namanya berubah menjadi Raden Sastro Drs. Widya Purnama. Pemberian gelar seperti itu bagai kalangan birokrat di lingkungan Pemerintahan Provinsi dianggap bergengsi menaikkan harga diri untuk mencari status, kehormatan, dan kemuliaan diantara sesama rekan kerja, kelompok, maupun masyarakat. Hal itulah yang kemudian mengentalkan feodalisme kerajaan di masa modern sekarang melalui pemberian nama gelar tersebut. Adanya sistem birokasi tradisional dalam abdi dalem punokawan dan birokrasi modern yang diwujudkan dalam bentuk abdi dalem keprajan bisa dibilang merupakan transformasi dari sistem birokrasi mataraman lama yang dikembangkan oleh Kasultanan maupun Kadipaten sebelum melakukan integrasi wilayah ke Republik Indonesia dengan menempatkan pangreh praja sebagai birokrasi yang mengurusi jalannya adminstrasi pemerintahan dan $a b d i$ dalem untuk urusan rumah tangga domestik kerajaan. Kini setelah bergabung ke dalam republik dan memperoleh status daerah istimewa, Yogyakarta diperbolehkan untuk mempertahankan unsur tradisionalitas pemerintahan sepanjang tidak melanggar kewenangan pemerintah pusat. Dalam hal ini, konsep birokrasi mataraman yang menjadi pola baku dalam sistem pemerintahan maupun birokrasi di Yogyakarta masih tetap dipertahankan dalam era modern ini. berikut ini model birokrasi mataraman modern Yogyakarta. 


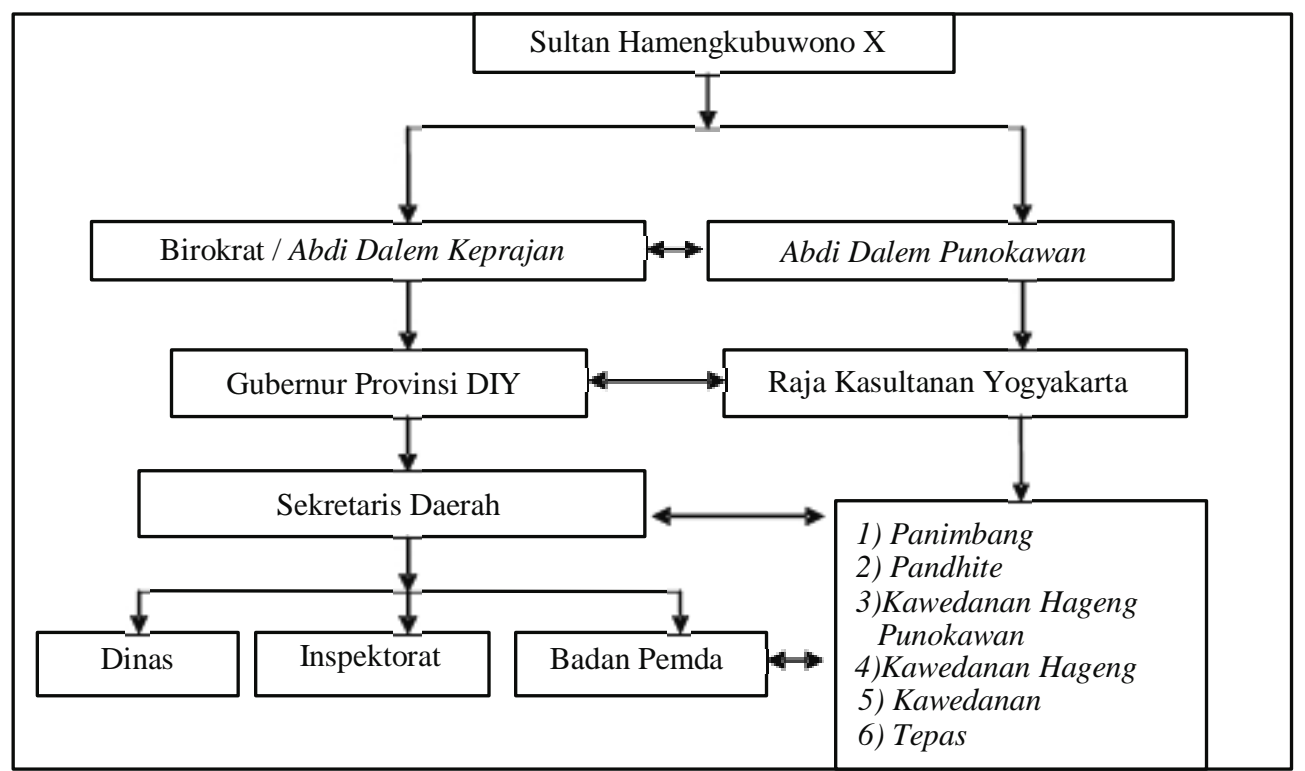

Sumber : Depdikbud (1999: 105)

\section{Gambar 1 : Struktur Birokrasi Patrimonialisme di DIY}

\section{Politisasi Birokrat Abdi Dalem dalam RUUK DIY}

Pengikatan birokrat menjadi abdi dalem merupakan langkah strategis dan politik bagi Sultan untuk kian memperkuat relasi patrimonial dengan masyarakatnya terlebih untuk menuai dukungan politis dan moril dari masyarakat dalam menggolkan RUUK DIY. Adapun langkah strategisnya dapat ditinjau dari upaya Sultan untuk memperkuat basis loyalitas di kalangan birokrat provinsi maupun nasional. Dalam level nasional sendiri, Sultan juga memberikan predikat abdi dalem kepada para pejabat tinggi negara di berbagai kelembagaan yang tujuannya untuk ikut andil dalam mempengaruhi proses perumusan RUUK di tingkat nasional sehingga secara tidak langsung Sultan mendapatkan kekuataan moril dalam menegosiasikan dengan para stakeholder yang merancang pembahasan RUUK tersebut. Dalam level lokal sendiri, kini telah terbentuk berbagai organisasi birokrasi yang terlihat dari munculnya berbagai paguyuban di tingkat akar rumput masyarakat yang terbentuk di berbagai kota / kabupaten DIY. Sebut saja, Ismaya (Ing Sedya Memetri Asrining Yogyakarta) yakni persekutuan birokrasi di ranah Pemerintahan Provinsi DIY dan Kabupaten Bantul, Semar di Kabupaten Sleman, Semar Semabaga di Kabupaten Gunung Kidul, Jaga Raga di Kabupaten Kulon Progo. Belakangan juga muncul paguyuban birokrat sejenis lainnya yang menamakan dirinya Apdesi yang memiliki basis massa kuat di kalangan petani dan pedagang pasar. Munculnya berbagai paguyuban ini merupakan bentuk warisan birokasi patrimonial yang sudah mengakar di struktur masyarakat. Umumnya birokrat yang tergabung dalam paguyuban tersebut 
adalah keturunan birokasi pangreh praja maupun birokrat yang kemudian diangkat menjadi abdi dalem, Posisi mereka sangatlah kuat karena mereka secara sosial budaya menempati posisi sebagai pengabdi kerajaan yang hingga kini masih diakui dan disegani oleh masyarakat Yogyakarta. Oleh karena itulah munculnya paguyuban birokrat berbasis abdi dalem sangatlah berdimensi politik bagi kelangsungan kekuasaan Sultan sebagai gubernur maupun raja. Dalam hal ini, terjadi hubungan timbal balik antara paguyuban birokrat dengan Sultan dalam RUUK DIY. Paguyuban birokrat sendiri membutuhkan Sultan sebagi raja dan gubernur untuk tetap bisa berkuasa atas tanah-tanah Sultan yang mereka gunakan di berbagai wilayah DIY. Tanah Sultan (Sultanate Ground) merupakan penghasilan rente ekonomi bagi para birokrat dengan menyewakan tanahnya kepada pihak ketiga untuk digunakan sebagai sumber usaha lainnya. Adapun pemberian tanah Sultan kepada paguyuban tersebut merupakan warisan sejarah kerajaan yang telah berlangsung lama sehingga jikalau Sultan tidak menjabat gubernur lagi dengan dilangsungkannya Pilgub. Maka secara otomatis, paguyuban sendiri akan kehilangan mata pencahariannya sebagai makelar tanah Sultan. Sementara bagi Sultan, munculnya paguyuban birokrat tersebut merupakan upaya Sultan untuk terus memberikan pengaruh politik, moral, maupun sosial-budaya kepada masyarakat DIY dengan mengimingimingi masyarakat akan mendapatkan tanah Sultan jika bersedia menjadi abdi dalem. Tentunya masyarakat DIY jelas tidak akan menampik permintaan raja tersebut mengingat budaya pakewuh (segan dan penghormatan tertinggi)

kepada Sultan karena selama ini mereka menggunakan tanah Sultan sebagai tempat tinggal maupun sumber ekonomi lainnya.Maka warisan patrimonialisme yang terwariskan dalam birokrasi sebagai agen kuasa dalam membentuk sikap loyalitas masyarakat merupakan corak utama politisasi birokrasi dalam RUUK DIY. Meskipun ditinjau dari perspektif otonomi daerah, setiap gubernur berhak untuk mengatur jajaran pemerintahannya. Namun dalam kasus Yogyakarta, posisi birokrat menjadi dilema antara pengabdi negara dan pengabdi kerajaan. Dalam satu sisi, birokrasi dibutuhkan untuk menjalankan roda pemerintahan sementara di sisi lain birokrasi harus menempatkan loyalitas tertinggi kepada gubernur selaku pimpinan tertinggi eksekutif di daerah. Perjuangan RUUK dengan menempatkan birokrasi sebagai basis patrimonialisme sendiri memang memiliki benang merah dengan kekuasaan kerajaan terdahulu. Sultan HB X melalui birokrasinya menginginkan agar kekuasaan kraton menjadi aktor utama dalam suksesi pemerintahan gubernuran di DIY. Makanya kemudian, corak khas birokrasi patrimonialisme yang berkembang di DIY berkaitan dengan isu RUUK ini cenderung bersikap status quo yakni tetap mempertahankan kondisi yang ada dan telah mengakar di masyarakat agar Sultan tetap menjadi gubernur. Pola status quo yang ditunjukkan oleh para birokrat di DIY mengindikasikan bahwa birokrasi juga menjaga posisi mereka agar mereka bisa mendapatkan rente ekonomi yang didapatkan dari 
hasil sewa lahan maupun pemberian posisi jabatan strategis lainnnya yang diberikan oleh pihak kerajaan. Oleh karena itulah, meski resistensi yang dilakukan oleh kaum birokrat tersebut mengatasnamakan sejarah dan jasa DIY kepada negara selama era revolusi fisik. Namun dibalik itu semua birokrat masih menjaga patrimoni secara ekonomi kepada Sultan. Maka tidaklah mengherankan apabila kini di DIY, birokrat yang berada di akar rumput senantiasa mengkampanyekan secara agitasi perihal RUUK DIY dan mengingatkan kepada masyarakat akan nilai arti sejarah hingga kemudian menggeruduk ke Jakarta berdemo di kantor Kemendagri.

\section{PENUTUP}

Relasi sinergisitas yang terbangun dalam sistem birokrasi yang terbangun antara sistem birokrasi tradisional (abdi dalem punokawan) dan sistem birokrasi modern (abdi dalem keprajan) semata-mata dilakukan untuk memperkuat kekuasaan patrimonialisme kerajaan di era modern sekarang ini. Posisi Sultan Hamengkubuwono dan Paku Alam sebagai raja sekaligus kepala daerah sangatlah strategis untuk tetap mempertahankan eksistensi kerajaan dengan mengkonversi nilai-nilai kultural ke dalam sistem birokrasi modern. Hal inilah yang kemudian menciptakan sistem birokrasi modern di pemerintahan provinsi menjadi birokrasi hibrid yakni birokasi modern yang terbalut dalam tradisionalitas. Abdi dalem keprajan merupakan contoh riil dari dualisme sistem birokrasi tersebut dengan mengikat berbagi unsur birokrasi mulai dari top level-bureaucracy hingga street level bureaucracy untuk menjadi abdi dalem di kerajaan. Abdi dalem keprajan adalah simbolisasi birokrasi patrimoni baru sekaligus pula sebagai agen kekuasaan tradisional kerajaan di mata masyarakat. Masyarakat Yogyakarta yang cenderung masih menilai posisi birokrat sebagai profesi terhormat yang mendapatkan status sosial bergengsi turut menambah nuansa patrimonialisme tersebut. Oleh karena itulah, birokrat kemudian menjadi mata rantai penghubung kerajaan dengan kondisi masyarakat di sekitarnya. Corak kultur birokasi mataraman yang masih menghinggapi pola kerja birokat di pemerintahan membuat ambiguitas dalam menilai jajaran birokrasi dalam pemerintahan Provinsi DIY apakah sebagai birokat pemerintahan atau birokrat kerajaan dikarenakan tidak ada batasan yang jelas pemisahnya. Meskipun demikian, dualisme sistem dalam birokrasi di Yogyakarta merupakan bentuk dinamika otonomi daerah terbalut sejarah kerajaan yang perlu kita hormati sebagai khazanah keilmuan dalam studi administrasi publik di Indonesia.

Adapun sumbangan keilmuan yang bisa diberikan dalam pembelajaran studi ini dalam ranah kajian administrasi negara ialah birokrasi patrimonialisme kini masih berkembang dalam struktur masyarakat prismatik dimana masih kuatnya local strongmen yang memiliki kekuasaan hegemonik melalui politisasi birokrasi dalam praktik demokrasi lokal yang berkembang di Indonesia. Kuatnya sumber kuasa berbasis kharismatiktradisional memang menjadi cara kuat bagi penguasa untuk kembali mengikat patrimonialisme kuat di kalangan 
masyarakat. Adapun posisi birokrat dalam stuktur patriminonialisme mengharuskan aktor ini bergerak secara statis hanya untuk menopang kekuasaan orang kuat tersebut. Walhasil, esensi otonomi daerah yang bertujuan mendekatkan negara untuk mensejahterakan masyarakat dalam konteks DIY berganti yakni mendekatkan masyarakat dalam stuktur patrimonial untuk menguatkan posisi Sultan sebagai gubernur dan raja.

\section{DAFTAR PUSTAKA}

Basri, M.(2010). Reformasi Sistem Administrasi Kepegawaian Menuju Netralitas Pegawai Negeri Sipil. Jurnal Kebijakan dan Manajemen PNS, 2(1), 18-22.

Buchori, M. (1982). Pola Tingkah Laku Birokrasi sebagai Akibat Pengaruh Kebudayaan. Prisma, Hal. 70-85.

Depdikbud. (1999). Sejarah Kerajaan Tradis ional Surakarta. Jakarta: Depdikbud.

Emmerson, D. K. (1983). Understanding The New Order: Bureaucratic Pluralism. Asian Survey, 28 (1), 124-144.

Kartodirdjo, S. (1987). Perkembangan Peradaban Priyayi. Yogyakarta: Gadjah Mada University Press.

Radjiman. (2002). Orang Jawa: Suatu Tinjauan Sosial Budaya Masyarakat Jawa, Surakarta: Penerbit Medio

Raharjo. (1998). Menyimak Kerancuan dalam Hubungan Lintas Struktur dan Kultur. Jurnal Ilmu Sosial dan Ilmu Politik, 2 (1), 88-103.
Ratnawati, Tri (2011). Antara Otonomi Sultan dan Kepatuhan pada Pusat di Era Reformasi: Studi Kasus Daerah Istimewa Yogyakarta. Governance, 2(1). 42-68.

Riggs, F. (1964). Administration in Developing Countries : The Theory of Prismatic Society. London: Sage Publication.

Santoso, P. B. (1997). Birokrasi Pemerintah Orde Baru: Perspektif Kultural dan Struktural. Jakarta: RajaGrafindo Persada.

Scott, J. C. (1993). Perlawanan Kaum Tani. Jakarta: Yayasan Obor Indonesia.

Sudaryanto, A. Hak dan Kewajiban Abdi Dalem dalam Pemerintahan Kraton Yogyakarta. Mimbar Hukum, 20 (1), Hal.164-177.

Suwarno, P. (1994). Hamengku Buwono IX dan Sistem Birokrasi Pemerintahan Yog yakarta, 1942 - 1974. Yogyakarta: Kanisius.

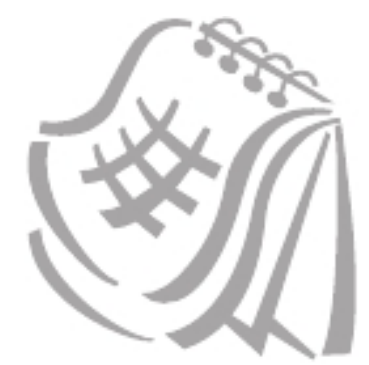

